\title{
Biomarkers in atrial fibrillation: a constant search for simplicity, practicality, and cost-effectiveness
}

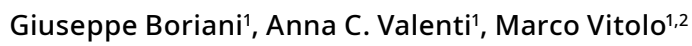 \\ 1 Cardiology Division, Department of Biomedical, Metabolic and Neural Sciences, University of Modena and Reggio Emilia, Policlinico di Modena, Modena, Italy \\ 2 Clinical and Experimental Medicine PhD Program, University of Modena and Reggio Emilia, Modena, Italy
}

RELATED ARTICLE

by Cichoń et al, see p. 269

Correspondence to: Prof. Giuseppe Boriani, MD, PhD, Cardiology Division, Department of Biomedical, Metabolic and Neural Sciences, University of Modena and Reggio Emilia, Policlinico di Modena, Via del Pozzo, 71, 41124 Modena, Italy, phone: +39059 4225836, email: giuseppe.boriani@unimore.it Received: February 1, 2021. Accepted: February 2, 2021 Published online: March 25, 2021. Kardiol Pol. 2021; 79 (3): 243-245 doi:10.33963/KP.15889 Copyright by the Author(s), 2021
The way we look at atrial fibrillation (AF) has radically changed in the last decade, switching from a mere arrhythmic conception to a complex nosological entity subtending structural and ultrastructural cardiac changes. ${ }^{1}$ Together with this acquisition, the concept of atrial cardiomyopathy has progressively matured and several circulating factors have been identified as markers of atrial disease and, by association, are assumed to be reliable in AF clinical assessment. ${ }^{2}$

However, despite the undebatable usefulness of biomarkers in many settings, their excessive or inappropriate use can lead to unnecessary and even harmful procedures as well as to a waste of healthcare resources. Thus, given the increasing number of available biomarkers and their several possible clinical applications, there is a need to clarify which ones are clinically effective and cost effective at the same time, and can substantially optimize the clinical decision-making process even in busy daily settings, representing a valuable "add-on" to physicians' practice (FIGURE 1).,

In the present issue of Kardiologia Polska (Kardiol Pol, Polish Heart Journal), Cichon et $\mathrm{al}^{5}$ aimed to evaluate the impact of basal and 4-week follow-up concentrations of biomarkers of left atrial overload on electrical cardioversion (CVE) efficacy. The study population included $82 \mathrm{pa}$ tients with persistent $\mathrm{AF}$ undergoing successful CVE and was divided into an obese and nonobese group with no significative difference in the distribution of the main features. Increased high-sensitivity C-reactive protein (hs-CRP) levels were found in the obese compared with the nonobese group, both at baseline and follow-up measurements. However, no relevant relation was highlighted between all the tested biomarkers (hs-CRP, N-terminal pro B-type natriuretic peptide [NT-proBNP], growth differentiation factor 15 [GDF-15], galectin 3, renalase, and copeptin) and the 4-week efficacy of CVE. ${ }^{5}$

Although the small study sample and the monocentric setting limit the generalization of the results, the present study ${ }^{5}$ enriches the open debate on the practical utility of biomarkers in the AF population.

As we know, AF pathophysiology articulates on a complex interplay between atrial remodelling (atrial enlargement and fibrosis), inflammatory substrate, and oxidative stress. All these factors are entwined in a bidirectional relation in which each one influences others' appearance, maintenance, and arrhythmia progression. Nowadays, the recommended approach to AF management is a holistic and integrated process that encompasses both patient and arrhythmia characteristics, in line with an individual-oriented clinical model resumed by the $A B C$ approach (A, avoid stroke; $B$, better symptoms control; $C$, cardiovascular and comorbidity risk factor control). ${ }^{6}$ From this perspective, and due to their dynamic nature, biomarkers may serve as an extra tool for an individualized decision-making process with the aim to provide a more targeted care. ${ }^{?}$

Many biomarkers have been evaluated with these purposes, from traditional markers of inflammation or atrial stretching (hs-CRP, NT-proBNP) and routinely available assays (eg, red blood cell distribution width $[\mathrm{RDW}])^{8}$ to extremely specific tests not currently employed 


\begin{tabular}{|c|c|c|c|}
\hline \multicolumn{2}{|c|}{ Type of biomarker } & Ideal biomarker & Clinical applicability in AF \\
\hline $\begin{array}{c}\text { Cardiac troponins } \\
\text { D-dimer } \\
\text { Natriuretic peptides } \\
\text { hs-CRP } \\
\text { Interleukins } \\
\text { RDW } \\
\text { TNF- } \alpha \\
\text { TGF- } \beta \\
\text { Fibrinogen } \\
\text { Galectin 3 } \\
\text { GDF-13, -15 } \\
\text { FGF-23 } \\
\text { Copeptin }\end{array}$ & $\begin{array}{c}\text { Renalase } \\
\text { CD40L } \\
\text { PAI } \\
\text { tPA } \\
\text { Cystatin C } \\
\text { vWF } \\
\text { Nucleosomes } \\
\text { miRNA } \\
\text { Myeloperoxidase } \\
\text { Metallopeptidase } \\
\text { Angiotensin II } \\
\text { HSPs } \\
\text { Procollagen peptides }\end{array}$ & $\begin{array}{c}\text { Availability } \\
\text { Practicality } \\
\text { Sensitivity } \\
\text { Clinical usefulness } \\
\text { in the decision- } \\
\text { making process } \\
\text { Impact on outcomes } \\
\text { Cost-effectiveness }\end{array}$ & $\begin{array}{l}\text { Thrombotic risk assessment } \\
\text { Bleeding risk assessment } \\
\text { Marker of underlying } \\
\text { cardiac disease } \\
\text { Prediction of AF recurrences } \\
\text { Prediction of AF progression } \\
\text { Prediction of hospitalization } \\
\text { Prediction of mortality and } \\
\text { CV adverse events } \\
\text { Patient targeting for AF } \\
\text { screening } \\
\text { Prediction of POAF }\end{array}$ \\
\hline
\end{tabular}

FIGURE 1 Biomarkers in atrial fibrillation: type, ideal characteristics, and clinical applicability Abbreviations: AF, atrial fibrillation; CD40L, cluster of differentiation 40 ligand; FGF-23, fibroblast growth factor 23; GDF-13, growth differentiation factor 13; hs-CRP, high-sensitivity C-reactive protein; HSPs, heat shock proteins; miRNA, microRNA; PAI, plasminogen activator inhibitor; POAF, postoperative atrial fibrillation; RDW, red blood cell distribution width; TGF- $\beta$, transforming growth factor $\beta$; TNF- $a$, tumor necrosis factor $\alpha$; tPA, tissue-type plasminogen activator; vWF, von Willebrand factor

or accessible (eg, peptides from collagen subtypes, microRNAs, nucleosomes, etc).

In the AF setting, biomarkers already entered some integrated risk scores for stroke and bleeding prediction (ABC-stroke, ATRIA, and $A B C$-bleeding), adding a modest, albeit statistically significant, improvement to conventional clinical-based scores and with a net clinical advantage limited to selected cases. ${ }^{9}$ Moreover, individual biomarkers cannot predict specific outcomes per se, and the need to integrate them with clinical items may lead to a further complication rather than simplification of clinical decision making. On the other hand, the actual evidence on biomarkers' role in predicting AF recurrences / progression is not homogenous and is often conflicting. In a large retrospective cohort of 1410 patients undergoing catheter ablation, BNP, hs-CRP, and estimated glomerular filtration rate were independent predictors of AF relapse after ablation with incremental predicting value when combining all 3 markers. ${ }^{10}$ Similarly, in a smaller cohort of patients with AF, Carballo et $\mathrm{al}^{11}$ found that basal values of hs-CRP and an immediate postablation assessment of NT-proBNP were related to a higher risk of AF recurrences, supporting the role of inflammation in triggering AF pathogenesis and relapse. Conversely, in other studies, no significant relationships were found between basal concentrations of various biomarkers and AF recurrences. ${ }^{12}$ It is noteworthy that Merino-Merino et $\mathrm{al}^{13}$ recently proposed that follow-up assessments rather than basal measurements may reflect those pathophysiological changes related to arrhythmic relapses and may be useful in patients' monitoring.
Thus, a question spontaneously arises: would a biomarker really change the daily management of AF patients? While research on biomarkers certainly contributes to uncover pathophysiologic aspects that lead us to a deeper comprehension of the arrhythmic substrate and its clinical manifestations, to date, no circulating factor alone seems to be able to substantially tip the balance in the clinical decision-making process, neither for patient rule-in nor rule-out.

In the setting of $\mathrm{AF}$, the potential value of combining several biomarkers in order to achieve an integrated assessment is still not fully established, as well as the precise impact of sex, age, and ethnicity on thresholds for specific decisions and interventions. To date, evidence supporting their role in guiding a clinicians' decision-making process is controversial, thus the clinical-based evaluation, pivoted on the medical history, physical examination, 12-lead electrocardiography, and cardiac imaging reports, remains the cornerstone of AF assessment. $3,5,6,14$

In conclusion, additional knowledge is needed to provide a daily clinical approach based on precision medicine and including biomarkers as an important reference for decision making. ${ }^{15}$

\section{ARTICLE INFORMATION}

DISCLAIMER The opinions expressed by the author(s) are not necessarily those of the journal editors, Polish Cardiac Society, or publisher.

CONFLICT OF INTEREST GB received speaker fees from Medtronic, Boston, Boehringer, and Bayer, outside of the submitted work. Other authors declare no conflict of interest.

OPEN ACCESS This is an Open Access article distributed under the terms of the Creative Commons Attribution-NonCommercial-NoDerivatives 4.0 International License (CC BY-NC-ND 4.0), allowing third parties to download articles and share them with others, provided the original work is properly cited, not changed in any way, distributed under the same license, and used for noncommercial purposes only. For commercial use, please contact the journal office at kardiologiapolska@ptkardio.pl. 
HOW TO CITE Boriani G, Valenti AC, Vitolo M. Biomarkers in atrial fibrillation: a constant search for simplicity, practicality and cost-effectiveness. Kardiol Pol. 2021; 79: 243-245. doi:10.33963/KP.15889

\section{REFERENCES}

1 Vitolo M, Proietti M, Harrison S, et al. The Euro Heart Survey and EURObservational Research Programme (EORP) in atrial fibrillation registries: contribution to epidemiology, clinical management and therapy of atrial fibrillation patients over the last 20 years. Intern Emerg Med 2020; 15: 1183-1192

2 Boriani G, Vitolo M. Atrial fibrillation in patients with cardiac implantable elec tronic devices: new perspectives with important clinical implications. Kardiol Pol. 2019; 77: 1119-1120.

3 Boriani G, Imberti JF, Valenti AC, et al. Managing atrial fibrillation: the need for an individualized approach even in the emergency department. Intern Emerg Med. 2020; 15: 9-12.

4 Boriani G, Bonini N, Albini A, et al. Cardioversion of recent-onset atrial fibrillation: current evidence, practical considerations, and controversies in a complex clinical scenario. Kardiol Pol. 2020; 78: 1088-1098.

5 Cichoń M, Mizia-Szubryt M, Olszanecka-Glinianowicz M, et al. Biomarkers of left atrial overload in obese and nonobese patients with atrial fibrillation qualified for electrical cardioversion. Kardiol Pol. 2020; 79: 269-276.

6 Boriani G, Vitolo M, Lane DA, et al. Beyond the 2020 guidelines on atrial fibrillation of the European society of cardiology. Eur J Intern Med. 2021 Jan 28. [Epub ahead of print].

7 Perrone MA, Zaninotto M, Masotti S, et al. The combined measurement of high-sensitivity cardiac troponins and natriuretic peptides: a useful tool for clinicians? J Cardiovasc Med (Hagerstown) 2020; 21: 953-963.

8 Malavasi VL, Proietti M, Spagni $S$, et al. Usefulness of red cells distribution width to predict worse outcomes in patients with atrial fibrillation. Am J Cardiol. 2019; 124: 1561-1567.

9 Esteve-Pastor MA, Roldán V, Rivera-Caravaca JM, et al. The use of biomarkers in clinical management guidelines: a critical appraisal. Thromb Haemost 2019; 119: 1901-1919.

10 Deng H, Shantsila A, Guo P, et al. Multiple biomarkers and arrhythmia outcome following catheter ablation of atrial fibrillation: the Guangzhou atrial fibrillation project. J Arrhythm 2018; 34: 617-625.

11 Carballo D, Noble $S$, Carballo $S$, et al. Biomarkers and arrhythmia recurrence following radiofrequency ablation of atrial fibrillation. J Int Med Res. 2018; 46: 5183-5194.

12 Begg GA, Karim R, Oesterlein T, et al. Left atrial voltage, circulating biomarkers of fibrosis, and atrial fibrillation ablation. A prospective cohort study. PLOS One. 2018; 13: e0189936.

13 Merino-Merino A, Saez-Maleta R, Salgado-Aranda R, et al. When should we measure biomarkers in patients with atrial fibrillation to predict recurrences? Am J Emerg Med. 2021; 39: 248-249.

14 Boriani G, Vitolo M. The 12-lead ECG: a continuous reference for the cardioogist. J Cardiovasc Med (Hagerstown). 2019; 20: 459-463.

15 Strano S, Toni D, Ammirati F et al. Neuro-arrhythmology: a challenging field of action and research: a review from the Task Force of Neuro-arrhythmology of Italian Association of Arrhythmias and Cardiac Pacing. J Cardiovasc Med (Hagerstown). 2019; 20: 731-744. 